RESEARCH REPORT

\title{
EFFECT OF DIFFERENT FOOT ARCH SUPPORTS ON DYNAMIC BALANCE IN NURSING PROFESSIONALS WITH FLATFOOT
}

\begin{abstract}
\section{BACKGROUND}

Flat foot, depletion of medial longitudinal arch affects almost $20 \%$ of adult global population; approximately $9-14 \%$ of schools going children are flat foot making the gender wise prevalence of about $13 \%$ girls and $7 \%$ boys, $11.25 \%$ population of age group between 18-25 years are diagnosed as flat footed.
\end{abstract}

\section{AIM}

The focus of this study is to device best possible strategy for the nurses to overcome their deformity and live as normal and pain free professional life as possible by providing foot supports that bring foot arches to normal or near normal position.

\section{METHOD}

The subjects were divided into two groups. Group A and Group B. Group A was asked to wear medial wedge support and group B was prescribed heel support for 3 weeks.

\section{RESULTS}

Result shows that both the orthosis are useful in forming the arch of foot, improving the dynamic balance and relieving the symptoms of flatfoot but medial wedge is found to be more efficient as compared to heel support.

\section{CONCLUSION}

It was concluded from the study that foot arch and heel support improves the flat foot, however medial longitudinal arch are found to be more therapeutically effective in recovering the foot arch in comparison to heel support.

\section{KEYWORDS}

Star Excursion Balance Test (SEBT), Flat Foot, Foot Arch, Medial Arch, Heel Support, Navicular drop test

\author{
Summaiya Naseem \\ Physiotherapist \\ Patel Hospital \\ summnaseem@gmail.com
}

Sumaira Imran Farooqui

Associate Professor

Ziauddin College of Physical Therapy

Ziauddin University

sumaira.farooqui@zu.edu.pk

\section{Ali Farhad}

Assistant Professor

Ziauddin College of Physical Therapy

Ziauddin University

alifarhadtharwani@gmail.com

\section{Ishrat Parveen}

Physiotherapist

Alamgir Welfare Trust

Parveeni28@yahoo.com

\section{Tayyaba Jabeen}

Physiotherapist

Dr. Essa Laboratory

jabeen931@gmail.com

[Naseem S, Farooqui SI, Farhad A Parveen I, Jabeen T. Effect Of Different Foot Arch Supports On Dynamic Balance In Nursing Professionals With Flatfoot. Pak. j. rehabil. 2017;6(2):14-19] 


\section{INTRODUCTION}

Flat foot, depletion of medial longitudinal arch affects almost $20 \%$ of adult global population; ${ }^{1,2}$ Approximately $9-14 \%$ of schools going children are flat foot making the gender wise prevalence of about $13 \%$ girls and $7 \%$ boys $^{3}, 11.25 \%$ population of age group between 18-25 years are diagnosed as flat footed ${ }^{4}$. Causes of pesplanus include Arthritis, trauma such as Foot or ankle injury, dysfunction, diabetes, posterior tibial tendon malfunction, and age ${ }^{5}$.There are Studies that have revealed that in most cases the deformity does not cause any functional limitation hence individuals' live normal life but researches have also documented pain, disturbance of balance and musculoskeletal abnormalities in individual with flatfoot. Long term presence of the deformity leads to pain in lower limb and back that in some cases is even exhibited in shoulder, head and neck. Change in foot height cause localized musculoskeletal abnormality, alteration in gait and lack of balance, both static and dynamic ${ }^{6}$, further increasing a risk of fall and participation restriction in daily activities. Working on improved foot functions and overcoming altered foot arch height can benefit individual's occupational activities and health related quality of life. The focus of this study is to device best possible strategy for the nurses to overcome their deformity and live as normal and pain free professional life as possible by providing foot supports that bring foot arches to normal or near normal position.

Evidences have proved that foot orthotics is valuable device to support the foot arch thus impacting positively on leg alignment, pain control and achieving normal gait?

Telfer in his study documented improvement in both dynamic and static stability in cavus feet but failed to identify the specific type of foot orthoses that is most efficient ${ }^{8}$. However, in a Randomized control trial Yazdi studied the impact of rigid foot orthoses on balance parameters in excessively pronate feet found a measurable decrease in medial-lateral sway in person with excessively prorated foot orthoses for four weeks?.

Specific type of foot orthotics can give beneficial effects on foot pain, gait and balance; further can maintain normal alignment of foot and mechanical correction if there is any ${ }^{10}$. Globally, lots of researches have been conducted on the topic but the researcher was unable to identify conclusive work on the specific topic in context of Pakistan.

Sojitra Ninin in her observational study included 20 subjects, 10 with flat foot and 10 with normal arched foot of 18-25 years of age; she evaluated their dynamic balance using $Y$ - balance test and concludes that Dynamic balance is not affected in flat feet individuals ${ }^{11}$.
The ability of an individual to maintain dynamic balance according to change in position of foot in pronation and supination on the bases of the height of arch was studied. 14 subjects for the supinated foot, 14 for pronated and 14 for the normal foot among 162 university students. Researcher found no change in dynamic balance in any of 3 positions (anterior, posterio-lateral and posterio-medial) ${ }^{12}$.

In a study that determined effect of the medial longitudinal arch height on a static and dynamic balance among female athletes, 45 subjects were classified into 3 groups with increased supination, pronation, and normal arch by using navicular drop test, standing balance test on one leg with the open eyes and the dynamic equilibrium of the persons by the Star Excursion Balance Test and Tukey test ${ }^{9}$. They conclude that changing the height of the medial longitudinal arch has the negative effect on the static and dynamic balances ${ }^{13}$.

Effects of the flat foot on running ability (short distance, middle distance, and long distance) of 18-25 years of age athlete ${ }^{10}$ was studied on 99 subjects that were classified into two groups: group A: flat foot and group B: normal foot . Data obtained as Independent Variable including 0-meter sprint, 600 meter run and 12 min- run/walk and Dependent variables including 100-meter performance time and 600-meter performance Time. Study found normal foot performing better in 100-meter sprint and 12 meter run test but no difference was found for 600 meter run test ${ }^{14}$.

20 subjects were included in a study to find the effectiveness of medial foot arch support on balance performance in flatfoot. The age of the subjects was between 18-25 years, performance of balance was found to be enhanced with the use of arch support in flat foot individuals ${ }^{15}$.

A systemic review was done on usefulness of SEBT's as a clinical assessment test for quantification of dynamic postural-control deficits from lower limb impairment. It concluded that the SEBT is a reliable measure and has validity as a dynamic test to predict risk of lower limb injury and also to identify dynamic balance deficit in people with a variety of lower limb conditions. It has also been found to be effective therapeutically as it was also found to be responsive to training programs in both healthy and in individuals with lower limb injuries ${ }^{16-18}$.

A total sway was found to be decreased by functional and UCBL inside was less than modified UCBL (Heel Raise) due to structural difference of orthoses and it improve the balance in patient with flexible flat foot, but in three orthoses there is no change in A-P and M-L sways ${ }^{19}$.

A pilot study concluded that medial heel skive technique is an effective tool to cure flat foot thus 
reducing pain and alleviating functional limitation hence insole is highly prescribed for flat foot individuals ${ }^{18}$.

The people who had more dynamic foot pronation showed a very good response in their foot biomechanics when they wear customized foot orthosis $^{17-19}$.

A study was designed to find a foot motion difference between flat footed and normal people it was concluded that people with flat foot walk with their foot in pronation and this pattern increases risk of overuse injury in foot ${ }^{20}$.

Flexible arch support study reported that medial force on knee is increased during walking and running that in turn increases knee Varus torque ${ }^{21}$.

Another systematic review established a relationship between foot posture and motion of lower limb during walking ${ }^{22}$.

Moreover, people with high arched foot have great force in medial fore foot region and those with normal or low arched feet have greater force in greater toe region, regardless of load it causes to generate a rigid lever during toe- off ${ }^{23}$. However, there is no effect of static and dynamic balance in individual with genu valgum and flat foot deformity except genu varum abnormality ${ }^{24}$.

\section{METHODOLOGY}

\section{Study Design}

Randomized Controlled Trial (RCT).

\section{Sampling Technique}

Enveloped method was used.

\section{Study Setting}

A tertiary health care center of Karachi, Pakistan.

\section{Study Period \\ 6-8 months}

\section{Study Method}

The study was performed on nursing professionals having flatfoot. The subjects were divided into two groups. Group A and Group B. Group A was asked to wear medial wedge support and group B was prescribed heel support for 3 weeks. Navicular drop test was performed to measure the effect of wearing support on arches at the day 1 and after the completion of three weeks of wearing of arch. SEBT was performed to measure alterations in their dynamic balance pre and post three weeks of wearing foot support.

\section{Inclusion criteria}

- People from nursing profession.

- Both Rigid and flexible bilateral flatfoot.

\section{Exclusion criteria}

- Recent lower limb and foot deformity

- Any health conditions like rheumatoid arthritis that might hinder the performance.

- Pregnancy

- Neurological disorder that affects the balance.

- Any visual, auditory, or systemic deficit.

- Subjects not willing to participate.

\section{Procedure}

1. Navicular drop test

Person should be in a non-weight bearing position for the testing leg. Mark the navicular tuberosity and draw a line from medial malleolus to base of big toe. Then measure the height of navicular bone with the subtalar joint in neutral. Now in weight bearing position same measurements will be taken. Navicular drop is the difference between first and second measurement. If the navicular drop value is $>10 \mathrm{~mm}$ than flat foot is present. ${ }^{22}$

\section{Star Excursion Balance Test (SEBT)}

To identify the improvement in the balance pre and post SEBT was performed in a manner as under:

\section{Test Procedure ${ }^{11-13}$}

Participants should do warm-up before starting the test. Warm-ups should correspond to the biomechanical and physiological type of test. Its duration should be 3-5 minutes.

\section{Conducting the test ${ }^{14-15}$}

- The participant should take off their shoes while wearing light cloths.

- The individual that has to perform the test is advised to maintain his balance on one leg, and then reach as far as possible by using the other leg in 8 different directions. If the person is standing on his/her left leg his/ her movement will be in following directions: anterior, anteromedial, medial, posteromedial, posterior, posterolateral, lateral and anterolateral.

- The individual should try to reach with one foot as far as possible and slightly touch the line before returning back to the starting position.

- Instructor should mark the point with the pencil at the point of contact on the floor of the individual either by toe or by heel.

- To calculate the distance reached in each extent direction, the point will be measured from the center point after the test. The distances should be recorded to the approximately $0.5 \mathrm{~cm}^{18}$.

- He should repeat the same procedure for all reach directions before changing foot.

- After they have completed a full task with both feet, the test will be repeated three times for each leg. 
- Once participant has performed 3 complete reaches with each foot in all directions then he is allowed to leave the testing area.

- In order to calculate the participant's SEBT score after the test. The instructor should have recorded the reach distance of each successful attempt.

- NOTE: Any imbalance and incomplete attempts will consider as a failed attempt. The participant should not hold anything to maintain their balance. - The participant must slightly touch their toe and or heel on the reach line while maintaining full control of their body, any heavy contact on the floor will be counted as a failed attempt.

\section{Evaluation of Test}

- The test instructor evaluates the person's SEBT performance score by using the following equation: - Average distance reached (R) in each direction $(\mathrm{cm})=\mathrm{R} 1+\mathrm{R} 2+\mathrm{R} 3 / 3$

- Relative distance in each direction (\%) = Average distance / leg length $\times 100$

- This should be calculated for both the legs in all direction, hence having 16 scores in total per individual.

\section{RESULT}

A paired t-test was applied on intervention variable on right/ left foot or both after individuals worn medial wedge in group A and heel support in group B for three weeks.

With both arch supports, arch height after intervention was significantly improved. With medial wedge in right foot pre-intervention, the navicular drop was $11.6 \pm 0.97$ and post-intervention the navicular drop was $8.2 \pm 1.47(\mathrm{P}=0)$ while in Left foot pre-intervention, the navicular drop was $11.2 \pm 0.86$ and post-intervention, the navicular drop was $8.0 \pm 1.27(\mathrm{P}=0)$. With heel support in right foot pre-intervention, the navicular drop was $11.6 \pm 0.96$ and post-intervention, the navicular drop was $9.5 \pm 1.76(\mathrm{P}=0)$ as compared to Left foot pre-intervention, where the navicular drop was $11.0 \pm 0.89$ and post-intervention, the navicular drop was $9.4 \pm 1.5(\mathrm{P}=0)$.

For further confirmation of the result gained from paired t-test we also used one sample test on post-intervention of both right and left foot, the mean difference in right foot with medial wedge was $8.2 \pm 1.43$ while with heel support was $9.5 \pm 1.76$ and in left foot with medial wedge was $8.2 \pm 1.43$ while with heel support it was 9.5 \pm 1.76 .

The improvement in dynamic balance was measured by SEBT test using 3 directions ( $Y$ balance test). In group with medial wedge pre intervention was $74.3 \pm 8.3$ and post intervention was $82.4 \pm 7.4$ while the group with heel support pre intervention was $72.4 \pm 7.1$ and post intervention was 74.2 \pm 7.2 .

Hence, our results shows that both the orthosis are useful in forming the arch of foot, improving the dynamic balance and relieving the symptoms of flatoot but medial wedge is found to be more efficient as compared to heel support.

\section{DISCUSSION AND CONCLUSION}

Due to flatfoot, the ability to distribute the weight equally on lower limbs is compromised in affected individuals as compared to normal persons ${ }^{25}$. To overcome this deficiency therapeutic footwear or foot orthoses are advised universally ${ }^{26}$. Other therapeutics techniques include strengthening exercises for the intrinsic and extrinsic muscles of the foot through sensory-motor training ${ }^{27}$. In this study, the altitude of the medial longitudinal arch was altered by providing two different types of foot arches for three weeks. he results obtained showed that descending distance of the navicular bone decreased from $11.6 \pm 0.97 \mathrm{~mm}$ before intervention to $8.2 \pm 1.47 \mathrm{~mm}$ after intervention with medial wedge in comparison to heel support in which the observed navicular drop was $11.6 \pm 0.96 \mathrm{~mm}$ before intervention to $9.5 \pm 1.76 \mathrm{~mm}$ after, indicating that the medial wedge was more effective. Study conducted by Allen \& Glasoe in 2000 exhibited that a normal arch can be formed through six weeks of strengthening exercises program by reducing the medial longitudinal arch successfully ${ }^{28}$. On the other hand, Lynn et al. $2012^{29}$, documented the efficiency of towel-curl exercises when they were conducted for four weeks while Jung et al. 2011, in his study used combined exercise approach with toe curl exercises and arch formation exercises, he reported that the hind foot angle significantly decreased while increasing foot intrinsic muscle strength ${ }^{30}$.

Telfer et al stated that variations in the arrangement of the arch of the sole affected balance and gait ability. The result obtained from this study is according to the study of Telfer et al, when dynamic balance was measured using YBT, both the medial wedge and the heel support group showed significant improvement in the balance outcome measured. The reason may be due to the fact that arches reduced maximum load reaction and improved leg stability thereby improves dynamic biomechanical effects ${ }^{31}$.

Hence it was concluded from the study that foot arch and heel support improves the flat foot, however medial longitudinal arch are found to be more therapeutically effective in recovering the foot arch in comparison to heel support. 


\section{REFERENCES}

[1] Hill CL, Gill TK, Menz HB, Taylor AW. Prevalence and correlates of foot pain in a population-based study: the North West Adelaide health study. J Foot Ankle Res. 2008;1 (1):2

[2] Bouchard M, Mosca VS. Flatfoot deformity in children and adolescents: surgical indications and management. J Am Acad Orthop Surg. 2014;22(10):623-32

[3] Umar MB, Tafida RU. Prevalence of flatfoot and anthropometric comparison between flat and normal feet in the Hausa ethnic group of Nigeria. JAPMA. 2013;103(5):369-73

[4] Bhoir T, Anap DB, Diwate A. Prevalence of flat foot among 18-25 years old physiotherapy students: cross sectional study IJBMAR. 2014;3(4):272-8.

[5] Robinson Jr DK, Erickson JJ, Lane III JF, Dave HY, inventors; Acushnet Co, assignee. Shoes with shank and heel wrap. United States patent US 8,074,379. 2011 Dec 13.

[6] Myerson MS. Adult Acquired Flatfoot Deformity.: Treatment of Dysfunction of the Posterior Tibial Tendon. JBJS. 1996 May 1;78(5):780-92.

[7] Telfer S, Abbott M, Steultjens M, Rafferty D, Woodburn J. Dose-response effects of customised foot orthoses on lower limb muscle activity and plantar pressures in pronated foot type. Gait \& posture. $2013 \mathrm{Jul}$ 1;38(3):443-9.

[8] Telfer S, Abbott M, Steultjens MP, Woodburn J. Dose-response effects of customised foot orthoses on lower limb kinematics and kinetics in pronated foot type. Journal of biomechanics. 2013 May 31;46(9):1489-95.

[9] Khoshraftar Yazdi N. Comparison of electrical activity of lateral and medial stabilizers of the patella and further diagnostically relevant risk factors in athletes with and without patellofemoral pain and in a Tai Chi group. https://pub.uni-bielefeld.de/publication/2303530

[10] Gribble PA, Hertel J, Plisky P. Using the Star Excursion Balance Test to assess dynamic postural-control deficits and outcomes in lower extremity injury: a literature and systematic review. Journal of athletic training. 2012 May;47(3):339-57.

[11] Sojitra N, Patel S. A Study To Compare Dynamic Balance Between Individuals With Flat Feet And Individuals With Normal Arched Feet Using Y-Balance Test-An Observastional Study. Indian Journal Of Physical Therapy. 2017 APR 2;5(1):36-40.

[12] Hyong $\mathrm{IH}$, Kang $\mathrm{JH}$. Comparison of dynamic balance ability in healthy university students according to foot shape. J Phys Ther Sci. 2016;28(2):661-4

[13] Hakimipour M, Fadaee E. The effect of the medial longitudinal arch height of the foot on static and dynamic balance of female college athletes. International Journal of Sport Studies. 2015;5(8):1004-1009
[14] Sharma J, Upadhyaya P. Effect of flat foot on the running ability of an athlete. IJO. 2016;2(1):119-23..

[15] Takata Y, Matsuoka S, Okumura N, Iwamoto K, Takahashi M, Uchiyama E. Standing balance on the ground-the influence of flatfeet and insoles. J Phys Ther Sci. 2013;25(12):1519-21.

[16] Robinson RH, Gribble PA. Support for a Reduction in the Number of Trials Needed for the Star Excursion Balance Test. Arch Phys Med Rehabil. 2008; 89(2): 364-370

[17] Munn J, Sullivan SJ, Schneiders AG. Evidence of sensorimotor deficits in functional ankle instability: a systematic review with meta-analysis. J Sports Sci Med. 2010Jan 1;13(1):2-12.

Fitzgerald D, Trakarnratanakul N, Smyth B,

[18] Caulfield B. Effects of a wobble board-based therapeutic exergaming system for balance training on dynamic postural stability and intrinsic motivation levels. J Orthop Sports Phys Ther. 2010 Jan;40(1):1 1-9.

Saeedi H, Mousavi ME, Majddoleslam B, Rahgo-

[19] zar M, Aminian G, Tabatabai Ghomshe F, Movahedi Yeganeh $M$. The evaluation of modified foot orthosis on muscle activity and kinetic in a subject with flexible flat foot: single case study. Prosthet Orthot Int. 2014 Apr;38(2):160-166 http://journals.sagepub.com/doi/pdf/10.1177/0309364613492170

Askary Kachoosangy R, Aliabadi F, Ghorbani M.

[20] Prevalence of flat foot: comparison between male and female primary school students. Iranian Rehabilitation Journal. 2013 Oct $15 ; 11(2): 22-4$.

Kerrigan DC, Franz JR, Keenan GS, Dicharry J,

[21] Della Croce U, Wilder RP. The effect of running shoes on lower extremity joint torques. PMR. 2009; 1 (12):1058-63.

Buldt AK, Murley GS, Butterworth $\mathrm{P}$, Levinger $\mathrm{P}$

[22] Menz HB, Landorf KB. The relationship between foot posture and lower limb kinematics during walking: a systematic review. Gait Posture. 2013 Jul 1;38(3):363-72.

Goffar SL, Reber RJ, Christiansen BC, Miller RB,

[23] Naylor JA, Rodriguez BM, Walker MJ, Teyhen DS. Changes in dynamic plantar pressure during loaded gait. Phys Ther. 2013 Sep;93(9):1175-84 Aboutorabi A, Zare-zadeh F, Saeedi H, Maleki M,

[24] Fardipour S. Effect of Orthopedic Shoe and Funconal Foot Orthosis on Stac Equilibrium in Flexible Flat Foot Juvenile. https://rehabilitationj.uswr.ac.ir/article-1-1588-fa.pdf

Korpelainen R, Orava S, Karpakka J, Sïra P,

[25] Hulkko A. Risk factors for recurrent stress fractures in athletes. Am J Sports Med. 2001 May;29(3):304-10

Noll $\mathrm{KH}$. The use of orthotic devices in adult [26] acquired flatfoot deformity. Foot and ankle clinics. 2001 Mar;6(1):25-36

Citaker S, Gunduz AG, Guclu MB, Nazliel B, Irkec

[27] C, Kaya D. Relationship between foot sensation and standing balance in patients with multiple 
sclerosis. Gait Posture. 2011 Jun 1;34(2):275-8

[28] Allen MK, Glasoe WM. Metrecom measurement of navicular drop in subjects with anterior cruciate ligament injury. J Athl Train. 2000 Oct;35(4):403-06

[29] Lynn SK, Padilla RA, Tsang KK. Differences in static-and dynamic-balance task performance after 4 weeks of intrinsic-foot-muscle training: the short-foot exercise versus the towel-curl exercise. J Sport Rehabil. 2012 Nov;21 (4):327-33
[30] Jung DY, Kim MH, Koh EK, Kwon OY, Cynn HS, Lee $\mathrm{WH}$. A comparison in the muscle activity of the abductor hallucis and the medial longitudinal arch angle during toe curl and short foot exercises. Phys Ther Sport. 2011 Feb 1;12(1):30-5

[31] Razeghi M, Batt ME. Foot type classification: a critical review of current methods. Gait Posture. 2002 Jun 1;15(3):282-91 